\title{
Pattern of anemia during pregnancy among patients in selected hospital in Bangladesh
}

\begin{abstract}
Background: Anemia in pregnancy is a common health problem. In developing countries, nearly half of all women and children are anemic. Anemia reduces work productivity and places at risk for poor pregnancy outcomes including increased risk of maternal mortality, perinatal mortality, premature births, spontaneous abortions and low birth weight.
\end{abstract}

Objective: The aim of this study was to assess pattern of anemia during pregnancy.

Methods: A cross sectional observational study was conducted among purposively selected 200 women attending in the outpatient department (OPD) of Obstetrics and Gynecology and Clinical Pathology department, BSMMU. Hemoglobin was measured by appropriate method. Descriptive statistics were used to analyze data.

Results: About 55\%, 33\% and 12\% women suffered from anemia at 2 nd trimester, 3 rd trimester and 1 st trimester of gestational period respectively. About $12 \%$ respondents had mean hemoglobin percentage of 55.83 in 1 st trimester. In 2 nd trimester $55 \%$ respondents had mean hemoglobin percentage 55.40 and remaining $33 \%$ had mean hemoglobin percentage 53.25 in 3 rd trimester. About $49 \%, 44 \%$ and $7 \%$ of the women were multipara, primipara and grand multipara respectively. Mean hemoglobin level was lower in multipara than in primipara. Mild, moderate and severe anemic was $70 \%, 27 \%$ and $3 \%$.

Conclusion: The mean hemoglobin level declines with the number of pregnancies of the respondents.

Keywords: anemia, pattern, pregnancy
Volume 2 Issue 4 - 2015

\author{
Rubaiyat-E-Mortaz,' Mesbah Uddin Ahmed, ${ }^{2}$ \\ Aklima Sultana, ${ }^{3}$ Md Saiful Islam,' Nasrin \\ Jahan,' Rahim MA, ${ }^{4}$ Tazul Islam ${ }^{5}$ \\ 'Department of Clinical Pathology, Bangabandhu Sheikh Mujib \\ Medical University, Bangladesh \\ ${ }^{2}$ Bangladesh University of Health Sciences, Bangladesh \\ ${ }^{3}$ Department of Obstetrics and Gynaecology, Bangabandhu \\ Sheikh Mujib Medical University, Bangladesh \\ ${ }^{4}$ Department of Epidemiology, National Institute of Preventive \\ and Social Medicine, Bangladesh \\ ${ }^{5}$ American International University Bangladesh, Bangladesh
}

Correspondence: Mesbah Uddin Ahmed, MS in Microbiology, Bangladesh University of Health Sciences (BUHS), Bangladesh, Tel +88017/2191479, Email mesba.lab@gmail.com

Received: February 25, 2015 | Published: June 09, 2015
Abbreviations: OPD, outpatient department; CDC, centers for disease control and prevention; BSMMU, bangabandhu sheikh mujib medical university; WHO, world health organization

\section{Introduction}

Anemia during pregnancy is a public health problem all over the world. According to WHO, prevalence of anemia is $56 \%$ in developing country and $18 \%$ in developed country among the pregnant women. ${ }^{1}$ Anemia affects $25 \%$ to $50 \%$ of the world population and $50 \%$ of pregnant women. ${ }^{2}$ Prevalence of anemia in pregnant women of Bangladesh was reported as $50 \%$ \& $59 \%$ according to two different surveys conducted on 1999 and $1998 .{ }^{3}$ Iron deficiency anemia is the predominant cause of anemia in pregnancy and it causes various problems like preterm delivery, low birth weight baby, high maternal and perinatal mortality, morbidity and delayed physical recovery following pregnancy. So early detection of iron deficiency is very essential. ${ }^{4}$ Centers for Disease Control and Prevention (CDC) recommend routine screening for iron deficiency anemia in pregnant women. During pregnancy the hemoglobin concentration declines during the first and second trimesters because of an increase in blood volume..$^{5}$ Again most of the women enter pregnancy with low iron reserve that frequently ends in iron deficiency anemia. ${ }^{6}$ In a normal pregnancy with single fetus, women need $800 \mathrm{mg}$ iron; $500 \mathrm{mg}$ for maternal hemoglobin mass expansion and $300 \mathrm{mg}$ for fetus and placenta. Another $200 \mathrm{mg}$ more is shed through gut, urine \& skin. So a total $1000 \mathrm{mg}$ iron is needed by a single pregnancy. ${ }^{7}$ If this requirement is not meet or if the woman is previously iron depleted then iron deficiency anemia develop. About $95 \%$ of anemia during pregnancy is due to iron deficiency. ${ }^{8}$ Iron deficiency anemia is the most common during pregnancy. ${ }^{9}$ According to a study conducted in Bangladesh, anemia during pregnancy is the commonest medical disorder that occurs in developing country and it directly causes maternal death for about $20 \%$ and act as a predisposing factor for another $20 \%$. Perinatal mortality is higher in anemic women and cardiac failure during labor due to severe anemia is an important cause of mortality. Anemia also affects maternal weight gain, immune status, more chance of infection and delayed wound healing. ${ }^{10}$ Correction of anemia is important because anemic women poorly tolerate blood loss. ${ }^{11}$ Anemia also has significant effect on the fetus. Maternal anemia may impair oxygen delivery to fetus and interfere normal growth of baby. Consequences of anemia increase the burden of health services. This study aimed to estimate the prevalence of anemia in pregnant women and will help to take appropriate measures for the policy makers to reduce the anemia in our women population.

\section{Materials and methods}

\section{Study site}

This was a cross sectional observational study.

\section{Study period}

This study was carried out during the time period from September 2011 to January 2012.

\section{Study place}

Study was conducted in the outpatient department (OPD) of Obstetrics and Gynecology and Clinical Pathology department, Bangabandhu Sheikh Mujib Medical University (BSMMU). It was purposively selected. 


\section{Study population}

All Pregnant women attending Obstetrics \& Gynecology outdoor for antenatal visit within the study period were included in the study population.

\section{Sample size}

Total 200 pregnant women were included conveniently in this study.

\section{Data collection instruments}

Structured questionnaire was used.

\section{Hemoglobin measurement}

Blood was drawn by finger prick with lancer after sterilization of the site with $70.0 \%$ alcohol. The hemoglobin test was done by using Sahli's haemometer. Anemic was determined according to World Health Organization (WHO) standard. Anemic respondents were divided into 3 groups according to their hemoglobin level i.e. Mild anemia (hemoglobin less than $11 \mathrm{gm} / \mathrm{dl}$ ), moderate anemia (hemoglobin less than $8 \mathrm{gm} / \mathrm{dl}$ ) and severe anemia (hemoglobin less than $6 \mathrm{gm} / \mathrm{dl})$.

\section{Data processing}

After collection, data were checked thoroughly for consistency and completeness. Data were checked after collection of data to exclude any error or inconsistency.

\section{Ethical issue}

All ethical issues, which were related to the research involved with human subjects, were followed according to the guideline of ethical review committee. First of all I had to submit protocol with questionnaire to ethical review board. After taking permission from board research was conducted. Verbal consent was taken from every respondent. Detail procedure was explained before data collection and voluntary participation was ensured. Confidentiality was also maintained.

\section{Results}

(Figure 1), (Table $1 \& 2$ ).

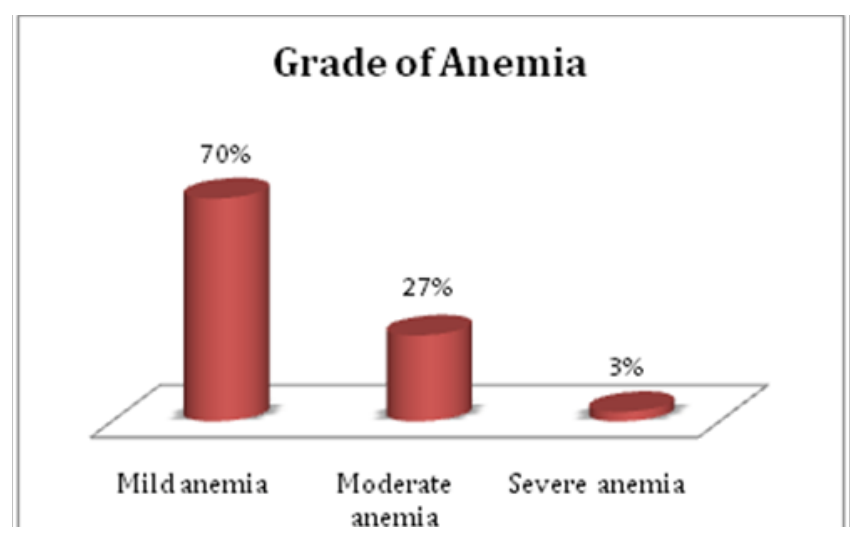

Figure I Distribution of anemia according to different grade. Majority (70\%) had mild anemia and $27 \%$ had moderate anemia. The rest $3 \%$ had severe anemia.
Table I Duration of pregnancy and mean hemoglobin percentage $(n=200)$

\begin{tabular}{|c|c|c|c|}
\hline $\begin{array}{l}\text { Duration of } \\
\text { pregnancy }\end{array}$ & $\begin{array}{l}\text { No. of } \\
\text { respondents }\end{array}$ & Percentage & $\begin{array}{l}\text { Mean } \\
\text { hemoglobin } \\
\text { percentage }\end{array}$ \\
\hline First Trimester & 24 & 12 & 55.83 \\
\hline $\begin{array}{l}\text { Second } \\
\text { Trimester }\end{array}$ & 110 & 55 & 55.4 \\
\hline Third Trimester & 66 & 33 & 53.25 \\
\hline Total & 200 & 100 & \\
\hline
\end{tabular}

About $12 \%$ respondents had mean hemoglobin percentage of 55.83 in $1^{\text {st }}$ trimester. In $2^{\text {nd }}$ trimester $55 \%$ respondents had mean hemoglobin percentage 55.40 and remaining $33 \%$ had mean hemoglobin percentage 53.25 in $3^{\text {rd }}$ trimester.

Table 2 Parity and mean hemoglobin percentage $(n=200)$

\begin{tabular}{llll}
\hline Parity & $\begin{array}{l}\text { No. of } \\
\text { respondents }\end{array}$ & Percentage & $\begin{array}{l}\text { Mean } \\
\text { hemoglobin } \\
\text { percentage }\end{array}$ \\
\hline Primi & 88 & 44 & 57.26 \\
Multi & 98 & 49 & 56.86 \\
Grand Multi & 14 & 7 & 53.57 \\
Total & 200 & 100 & \\
\hline
\end{tabular}

Relation between parity and mean hemoglobin percentage shows that $44 \%$ and $49 \%$ primipara and multipara had mean hemoglobin percentage of 57.26 and 56.86 .About $7 \%$ grand multipara had mean hemoglobin percentage 53.25 .

\section{Discussion}

Study revealed that among the respondents majority had mild anemia. This may be due to low intake of nutritive food. In first trimester about $12 \%$ respondents had mean hemoglobin percentage of 55.83 . Vomiting tendency and nausea may be responsible for this situation. Study conducted in Nigeria showed that the prevalence of anemia in pregnancy is $24.5 \%$. About $55 \%$ respondents had mean hemoglobin percentage 55.40 and remaining $33 \%$ had mean hemoglobin percentage 53.25 in second and third trimester respectively. In case of parity and mean hemoglobin percentage study revealed that $44 \%$ and $49 \%$ primipara and multipara had mean hemoglobin percentage of 57.26 and 56.86. Imbalance of food distribution and poverty may be the cause of it. One showed that adolescent primigravidae had the lowest mean hemoglobin concentration and the highest prevalence of anemia followed by adult primigravidae, adult multigravidae and adolescent multigravidae. ${ }^{12}$

\section{Conclusion}

The mean hemoglobin level declines with the number of pregnancies of the respondents.

\section{Acknowledgements}

None. 


\section{Conflict of interest}

The author declares no conflict of interest.

\section{References}

1. Bangladesh Bureau of statistics (BBS). Statistical pocket book of Bangladesh. Bangladesh: Bangladesh Bureau of statistics; 2013. 522 p.

2. Datta DC. Medical and surgical illness complicating pregnancy. In Dutta DC, Hiralal K, editors. D C Dutta's Textbook of Obstetrics. India: New world Publication Co; 2014. p. 276-280.

3. Brabin BJ, Ginny M, Sapau J, et al. Consequences of maternal anemia on outcome of pregnancy in a malaria endemic area in Papua New Guinea. Ann Trop Med Parasitol. 1990;84(1):11-24.

4. Akand AH. Incidence of anemia in pregnancy. Journal of the Pakistan Medical Association. 1970:149-153.

5. Lewis SM, Bain BJ, Bates I. Basic haematological techniques. In: Lewis SM, et al. editors. Dacie and Lewis Practical Haematology. USA: Elsevier publisher; 2001. p. 19-46.

6. Bessman JD, Gilmer PR, Gardner FH. Improved classification of anemia by MCV and RDW. Am J Clin Pathol. 1983;80(3):322-326.
7. Li CH, Lee ACW, Mak TWL, et al. Transferrin saturation for the diagnosis of iron deficiency in febrile anemic children. The Hong Kong Practitioner. 2003;25:363-366.

8. Christensen RD, Ohles RK. Anemia unique to pregnancy \& the perinatal period. In: Greer JP, et al. editors. Wintrob's Clinical Hematology. USA: Lippincott Williams \& Wilkins publisher; 2003. p. 1467-1473.

9. Fairbacnks VF, Beutler E. Iron Deficiency. In: Beutler E, et al. editors. Williams Hematology. USA: McGRAW HILL publishers; 2001. p. 447-464.

10. Dugdale AE. Prediction of iron and folate deficiency anemia from standard blood testing: the mechanism and implications for clinical medicine and public health in developing countries. Theor Biol Med Model. 2006;3:34.

11. Lin L, Ren J, Zeng C. Mean corpuscular volume and red blood cell volume distribution width in the diagnosis of iron deficiency anemia in pregnancy. Zhonghua Fu Chan Ke Za Zhi. 1997;32(2):81-83.

12. Gwarzo MY, Ugwa EA. The pattern of anemia in northern Nigerian pregnant women. J Med Med Sci. 2013;4(8):319-323. 